\title{
Mundos Virtuales y Pantallas
}

\author{
Screens and Virtual Worlds
}

- Rodrigo Martin Iglesias

Universidad de Buenos Aires, Argentina

rodrigo.martin@fadu.uba.ar

\begin{abstract}
The paper deals with the problem of the screens and its virtuality in the contemporary world from four analytical and hermeneutical perspectives: A genealogical perspective: The historical approach to the development of screens allows us to outline genealogical networks. An analogical perspective: which transforms the image re-presentation of the real, the production of the Real. A phenomenological perspective: in which our knowledge of reality is conditioned by our perception and this in turn by our senses. And a technological perspective: Outside any metaphor, what unites screens is its operability as a technical device.
\end{abstract}

Keywords: Screens, Virtuality, Devices, Media, Interfaces

\section{Introducción}

Las pantallas nos confrontan diariamente con su inmaterialidad, toda luminiscencia, y nos presentan sus sucesivos recortes del mundo, bidimensionales, literalmente superficiales. Un mundo presente que, curiosamente, contradice las predicciones de Bazin sobre la desaparición de la pantalla (cine total), al menos por ahora. Tal vez se trate de un canto de cisne, un proceso de proliferación que sólo preanuncia la saturación y la obsolescencia. Las pantallas, como soportes de la visualidad, han sido, son y serán uno de los dispositivos técnicos cruciales para entender nuestra civilización actual. En palabras de Jean-Louis Comolli: "Las máquinas de lo visible (máquinas bien humanas: de la webcam al aparato fotográfico descartable, pasando por los satélites, las televisiones las pantallas y cámaras de toda suerte) están desde ahora en el centro de gravedad de nuestras sociedades -tuve la tentación de escribir: de toda sociedad humana" (Comolli, 2002).

Quizás esta sea la causa por la cual los enfoques acerca de las pantallas son tantos y tan heterogéneos. Desde Lev Manovich a André Bazin, pasando por Derrick de Kerckhove, Paul Virilio, Erkki Huhtamo, Tom Gunning, Don Ihde, Nicholas Vardac, Edward Wachtel, Vivian Sobchack, Roger Silverstone, Jean-Louis Comolli, Regis Debray, Philippe Dubois o Marshall McLuhan, el universo de las pantallas ha sido explorado, analizado, descrito, explicado, caracterizado, historiado, poetizado, interpretado y teorizado. A pesar de esta enorme actividad, o tal vez debido a ella, el conocimiento sobre las pantallas es muchas veces contradictorio o redundante. Podemos encontrar autores que parecen ignorar la existencia de otros cuyos dichos parecen repetir exactamente sus argumentos o refutarlos completamente. Se experimenta, así, un panorama de dispersión y deriva, donde la complejidad teórica y la exuberancia retórica son moneda corriente.

\section{Perspectiva genealógica}

El enfoque histórico sobre el desarrollo de las Pantallas, de los sistemas de proyección de imágenes en general, desde la cámara obscura hasta la realidad virtual, nos permite esbozar líneas de fuga, redes genealógicas, que nos ayuden a entender los cruces disciplinares y pongan en perspectiva las lógicas implícitas en los medios. Cámara obscura, linterna mágica, fantasmagoría... toda una serie de dispositivos técnicos de proyección de imágenes que anteceden a las pantallas actuales y las hacen comprensibles como fragmento armónico de una sinfonía mayor, como gesto incluido en una continuidad con otros gestos, en un movimiento que toma sentido cuando uno se aleja lo suficiente para apreciar su amplitud, evitando la miopía de lo coyuntural. Ya a fines del siglo XVIII la idea de la pantalla de chimenea (mampara contra chispas) fue adaptada a la finalidad de mostrar las pinturas transparentes en formas nuevas y sorprendentes. Tales pinturas, "transparencias de luz de luna" o "diaphanoramas", como aquellas de los alemanes Georg Melchior Kraus y Franz Niklaus König, fueron montadas en marcos autoportantes de madera.

Entre estos dispositivos la fantasmagoría aparece a finales del siglo XVIII. Según Erkki Huhtamo (Huhtamo, 2001), en la Fantasmagoría le eran mostradas al público imágenes proyectadas desde detrás de la pantalla, con una 
linterna mágica de gran movilidad (a menudo montadas sobre ruedas y moviéndose a lo largo de rieles). Uno de los propósitos era crear una experiencia sensorial total. Este objetivo fue atendido por la tecnología oculta. Los feriantes de la Fantasmagoría hicieron lo posible por mantener en secreto su maquinaria, pretendiendo que su show nada tenía que ver con las viejas linternas mágicas. Incluso hicieron esfuerzos para ocultar la presencia de la propia pantalla hundiendo a la audiencia en la oscuridad total y sólo entonces abriendo las cortinas. Las figuras proyectadas fueron presentadas como "apariciones" que volaban libremente por la sala. No sólo fue un desarrollo posterior del espectáculo de linterna mágica, también estuvo basado en el espectáculo de sombras.

En efecto, la mayoría de las versiones del teatro de sombras se construyeron con disposiciones esencialmente similares del aparataje de la Fantasmagoría. El público se sienta delante de la pantalla, mientras que los artistas operan sus títeres de sombra detrás de ella, entre la pantalla y la fuente de luz. Para las personas no familiarizadas con tales espectáculos, la presencia de la misteriosa "caja de proyección" apenas disminuía la "magia" del evento. De hecho, puede haber servido como una atracción adicional. De manera similar, el público de las primeras películas a menudo admiró el cinematógrafo como una maravilla tecnológica, tanto como las imágenes en movimiento que producía.

Un texto de 1846 declaraba: "La linterna mágica es una especie de microscopio lucernal, su objetivo es obtener una representación aumentada de las figuras, sobre una pantalla en una habitación oscura". A lo largo del siglo XIX, el tamaño de la pantalla, el auditorio y la imagen proyectada se hicieron más grandes. Esto fue posible gracias al desarrollo de fuentes deiluminación nuevas y más potentes (focos de oxi-hidrógeno, lámparas de arco). A fines del siglo XIX, especialmente en Estados Unidos, la linterna mágica fue incluso llevada al exterior para proyectar grandes anuncios y resultados de las elecciones en los edificios públicos, ahora re-definidos como pantallas de proyección gigantes. En el siglo XIX también proliferaron diversas formas de imágenes iluminadas por detrás, que van desde "lithophanes", figuras de porcelana colocadas en las pantallas de las lámparas, o en marcos decorativos de madera o metal; hasta máquinas domésticas para ver, como el enorme Megalethoscope, diseñado para la visualización de grandes fotografías de albúmina con filtros coloreados a mano adheridos a la parte trasera. Mirando a través de una "capucha" de visión y abriendo al mismo tiempo una puerta en la parte posterior del dispositivo, las fotografías en blanco y negro eran transformadas en fabulosos y coloridos espectáculos. Estos y otros muchos tipos de "pantallas" anticiparon el futuro rol y ubicación de la pantalla del televisor, aunque su potencial de transmisión de información visual o representación del movimiento era limitado. A medida que la producción y exhibición de películas consolidaban su papel como principales industrias de entretenimiento -desde la década de 1910 en adelante-, las otras atracciones pasaban gradualmente a un segundo plano: el centro estaba reservado a los placeres de la pantalla. Ya en 1910 el Moving Picture World escribía que "a la gente le gusta ver en la pantalla aquello sobre lo que han leído", en referencia a sus preferencias fílmicas.

Por otro lado, hay otra línea que llega hasta las actuales pantallas electrónicas y cuyo origen es situado por diversos autores en la pantalla de radar, nuevo medio que Manovich llama pantalla dinámica. "Desde el primitivo barrido de un contorno y el rastreo de un punto, estas pantallas comenzaron a convocar a un ojo ya no tan atento al campo como al surgimiento puntual de algo a seguir, a controlar, y cuya manifestación en pantalla era el correlato de un evento sincrónico. Origen del monitoreo electrónico, del display de los instrumentos, de las pantallas de computadoras." (Manovich, 2000). El siguiente paso de este despliegue evolutivo será dado en los años 50 por Forrester, cuando incorpora a la pantalla electrónica como interfase de visualización de los sistemas de uso bélico (Whirlwind, SAGE). Aquí la innovación fundamental será la interactividad dela pantalla. Al conectarla con otra serie de dispositivos e interfases, la pantalla viene a ser el output de sistemas mucho más complejos, que también contemplan la posibilidad del input. De este modo, el usuario ha dejado ya de ser un simple espectador. "El ojo en contacto con esa computadora ya aparecía íntimamente ligado a la mano, tanto como poco después, en la lógica de usos de la tecnología televisiva, el control remoto se revelaría como elemento decisivo de la actividad espectatorial de las últimas décadas. De modo aún balbuceante en la experiencia televisiva, pero totalmente decidido en el contacto cotidiano con la imagen digital, esta superficie ha mutado en pantalla interactiva." (Manovich, 2000).

\section{Perspectiva analógica}

El diccionario de la Real Academia de la lengua Española nos dice en su tercera acepción que una Pantalla es un "Telón sobre el que se proyectan las imágenes del cinematógrafo u otro aparato de proyecciones". Esta definición nos acerca al mundo del cine y el teatro ("telón"), pero ya contempla la posibilidad de la existencia de "otro aparato de proyecciones", a la vez que pone a la pantalla como receptora de imágenes proyectadas. Esta definición dejaría afuera a las pantallas emisoras de imágenes (luz), como las de computadoras y televisores. En su primera acepción nos dice que una Pantalla es una "Lámina que se sujeta delante o alrededor de la luz artificial, para que no moleste a los ojos o para dirigirla hacia donde se quiera". Esta definición nos acerca al origen etimológico de la palabra (quizá del català pantalla, y este cruce de pàmpol, pantalla de lámpara, con ventalla, pantalla de lámpara) y se presenta como mucho más interesante que la anterior, por lo que tiene de operativo. Sin embargo, nuevamente nos resulta insuficiente para abarcar el mundo de las pantallas por completo.

Visera, mampara, biombo, persiana, globo, cancel, telón, reflector, quitasol, toldo, cubierta, placa, tela, tapadera, encubridor, nube, sombra, visor, lámina, monitor, televisión, 
cine, pantalla chica, pantalla grande, pantalla, pantallas... Una dispersión de sentido que se justifica a partir de la importancia de la analogía como instrumento de comprensión y apropiación. En palabras de Gunning: "La naturaleza se extiende con la analogía, ella se (re)define también por medio de lo analogizable. El ejemplo de la foto científica muestra acabadamente cómo, gracias a las prótesis ópticas con que se provee la visión considerada natural (microscopio, etc.) la percepción gana una infinidad de nuevas imágenes, hasta las representaciones que uno podría calificar como abstractas o ficticias, si no pertenecieran a la intimidad de una naturaleza hasta entonces jamás avistada. Es en relación con esos confines (realismo concreto, realismo abstracto) que balizan la cantidad de analogía que la fotografía lleva a un nuevo espectro, que puede comenzar una liberación de la pintura por la fotografía, y que esta última, a su vez, sufra la influencia de la primera." (Gunning, 2002).

El ojo ve luz, una serie de frecuencias de ondas-partículas que van desde el límite infrarrojo hasta el ultravioleta. Pero también ve sombra, también percibe la ausencia, una ausencia de luz que ayuda a construir el sentido, así como el silencio entre las palabras o las notas musicales. Hemos visto que la pantalla es aquello que media entre la luz y el ojo, reflejándola, filtrándola, ocultándola, dándole forma. Ya en sociedades antiguas como China y Japón la pantalla tuvo muchos usos, dado que era portátil y podía ser erigida y desplegada, según fuese necesario, en diferentes partes de un edificio, cumpliendo así con ambas funciones, arquitectónicas y decorativas. También podía servir como separador de ambientes, una pared y un lugar de ocultación. Un lugar de ocultación. Quizás su característica más notable sea esta doble función de mostrar y ocultar. Pantallas ocultando lo visible, pantallas ocultando la fuente de luz; pantallas mostrando lo que está en otra parte y pantallas emitiendo imágenes lumínicas. Pero, por sobre todo, pantallas que al mostrar ocultan y al ocultar muestran, en una aparente contradicción que las define. La pantalla como celosía, como velo, y la misma pantalla del velador como instrumento de proyección. El velo y la vela, la imagen doblemente velada, la imagen re-velada versus la imagen de-velada, curioso juego que nos acerca también al mundo de la fotografía. Toda una serie de derivas que nos aproximan y nos alejan de los desvelos de la imagen, una yuxtaposición pulsante de misterios y revelaciones.

Erkki Huhtamo en su Elements of Screenology (Huhtamo, 2001) comenta cómo el espectador está físicamente relacionado con la pantalla en el espacio (de visión) y, al mismo tiempo, mentalmente relacionado con el espacio en la pantalla. La noción de la pantalla cambia en el tiempo y lo mismo ocurre con esta relación. Explica también que el objetivo final es la historia de "la(s) práctica(s) de pantalla", tal historia debe incluir no sólo la evolución de los diferentes tipos de pantallas y las interconexiones entre ellas, sino también tener en cuenta su uso como parte de diferentes aparatos mediáticos y como agente de cambio de valores culturales, sociales y económicos. Según Huhtamo, fue durante los comienzos del siglo XIX que la palabra "pantalla" ("screen") comenzó a alcanzar significados que anticiparon su uso actual dentro de la cultura y los medios de comunicación, esto es, como un medio para visualizar y transmitir imágenes.

La primera aparición de este tipo registrada en el Oxford English Dictionary proviene de 1810 y dice: "Hacer Pantallas Transparentesparala Exhibición delaFantasmagoría"("Tomake Transparent Screens for the Exhibition of the Phantasmagoria"). El mismo autor nos aporta definiciones que nos pueden ayudar a trazar el contorno de la Pantalla: "A covered framework, partition, or curtain, either movable or fixed, which serves to protect from the heat of the sun or of a fire, from rain, wind, or cold, or from other inconvenience or danger, or to shelter from observation, conceal, shut off the view, or secure privacy; as, a fire-screen; a folding-screen; a window-screen, etc.; hence, such a covered framework, curtain, etc., used for some other purpose; as, a screen upon which images may be cast by a magic lantern; in general, and shelter or means of concealment". (Definición de 'screen', The Century Dictionary and Cyclopedia, 1911 -orig.1889-). Más allá de los elementos normales, el Century Dictionary and Cyclopedia también consigna que era utilizada para proporcionar una protección de "otras molestias o peligro, o refugiar de la observación, ocultar, apartar de la vista, o asegurar la privacidad". Nuevamente el lugar de la ocultación (concealment).

Respecto de la aparición de estos "aparatos" o "máquinas" en relación a una superficie de proyección Philippe Dubois afirma que "...las máquinas de imágenes son particularmente antiguas, así como las máquinas de lenguaje. Mucho más antiguas que todo cuanto surge de lo que se ha dado en llamar las "artes mecánicas". De modo que la fotografía no representa de ninguna manera el origen histórico de las máquinas de imágenes. Es evidente, por ejemplo, que todas las construcciones ópticas del Renacimiento (los "portillons" de Durero, la tavoletta de Brunelleschi, las diferentes camera obscura, etc.) con el modelo perspectivista monocular que presuponen, fueron, desde el Quattrocento, las máquinas para concebir y fabricar imágenes de los pintores-ingenieros del Renacimiento: verdaderos tekhné optike que contribuyeron a fundar una forma de figuración "mimética" basada en la reproducción de lo visible, tal como se da a la percepción humana, aún bajo su condición de intelectualmente elaborada e inclusive calculada." (Dubois, 2000).

La Gran Analogía que sostiene a la Pantalla es aquella que transforma a la imagen en re-presentación de lo real. Es en este sentido donde funciona la "figuración mimética" de la que habla Dubois y se funda míticamente en la mentada "tavoletta" de Brunelleschi. Se trata de una estructuración arquitectónica del mundo visible, incluso reconfiguración de lo visible, de la propia visibilidad, y que se verifica en el profundo interés de los pintores-arquitectos renacentistas por la anatomía del ojo y el naturalismo del arte, y el furor de re-producción de lo real visibilizado. Algo que hoy aparece sumamente actual cuando pensamos en la imagen de síntesis y la cultura visual contemporánea, una supuesta re-presentación que siempre, 
indefectiblemente, oculta una evidente presentación, una producción de lo real. De este modo, volviendo a la "tavoletta", Raymond Bellour confirma nuestra intuición: "Se sabe que en el espejo sostenido por el sujeto en el experimento de Brunelleschi vienen a componerse dos planos heterogéneos: la pintura de un monumento concebido de acuerdo a las modalidades de la perspectiva que se inventa, y una superficie de plata bruñida, "de manera que el aire y los cielos naturales se reflejen, lo mismo que las nubes que se dejan ver, empujadas por el viento, cuando éste sopla."

Primero en su Théorie du nuage, luego en su libro sobre la perspectiva, Damisch remarca el valor de index de esas nubes, "mostradas" más que "demostradas", escapando por la fluidez de su materia a la racionalización perspectivista (de ese modo la teoría es construida por una exclusión que el prototipo -y con él la pintura- reconoce pero modera, ligando los dos planos, para dar cuenta de toda la naturaleza)." (Bellour, 1999). Incluso podemos decir que, mucho antes del desarrollo de la computadora, los espejos fueron utilizados como un medio para la simulación visual y que con ellos los mundos virtuales ya han sido simulados durante cientos de años. La capacidad de capturar el mundo real y reflejarlo de nuevo a la vida verdadera o incluso de forma distorsionada fue durante mucho tiempo el privilegio exclusivo del espejo. Hoy en día esta habilidad es emulada a través de tecnologías de medios digitales, incluso en su carácter más mágico: el de proponer un otro mundo al que sería posible entrar, traspasando la membrana dimensional que lo separa del nuestro. Pantallas cada vez más inmersivas que nos invitan a cruzar a través del espejo.

La gran analogía de la que hablamos no reduce la complejidad o la polisemia de la Pantalla previamente desarrollada. Ésta sigue fundada en una triada sintética de contradicción, redundancia y ambigüedad; una suerte de oxímoron tautológico. Sin embargo, lo que la analogía sí nos permite es explicar uno de los roles cruciales que las pantallas juegan en el montaje del escenario de lo real, en palabras de Bellour: "Esta impresión de analogía, por cierto, sólo puede parecer natural porque es construida, incluso aunque se funde sobre la fisiología de la visión. Pero es precisamente porque indudablemente, por vez primera en la historia- la impresión de analogía ha sido el objetivo de una construcción tan deliberada (tanto al nivel de la perspectiva como del sujeto que la percibe) que ha sido capaz de retirarse como tal y acentuar en la percepción del arte la cuestión de una identidad -parcial, relativa, pero constitutiva y constituyente- entre la obra y el mundo natural. Más precisamente, la misma percepción, como fuente del arte, viene entonces al primer plano, sea por la afirmación de un punto de vista común entre arte y ciencia o por la reivindicación de una cierta autonomía del arte que se exige desde el tránsito de la primera a la segunda fase del Renacimiento. Pero lo esencial, al menos aquí, es el hecho de que este ascenso de la visualidad sea más bien llevado a concebirse según un pensamiento y ciertas técnicas, al punto de que ellas se convierten en garantes de una capacidad de analogía, cuyos problemas son planteados por las técnicas mismas." (Bellour, 1999).

A partir de esta construcción, el Arte (las artes) en conjunto se expanden y transforman la realidad del mundo - la naturaleza - en la que participan, pero manteniendo en el interior de ese mundo una distancia entre su captura en tanto tal y su captura en tanto que imagen -a partir de la prueba común de la visión "natural". Incluso se pone en tela de juicio la propia entidad de la realidad y la construcción que de ella hacen nuestros sentidos. Sin caer en un empirismo escéptico, podemos decir con Bellour que "...lo que se llama la "realidad" del mundo está ligada a la proliferación de imágenes. Ellas parecen emanar de él desde que su punto de referencia es un mundo natural y divino que creemos ver directamente. Pero es el ojo el que asegura el vínculo entre el mundo y sus imágenes, dado que es quien lo percibe. (...) La acción perceptiva se fija de manera más precisa en torno de la impresión de analogía desde el momento a la vez real y simbólico (...) las diversas modalidades de puesta en forma de lo visible se encuentran mejor cualificadas en relación a la cantidad de analogía que son susceptibles de producir." (Bellour, 1999).

\section{Perspectiva fenomenológica}

En una continuidad con el capítulo anterior que inicialmenteno hubiésemossupuesto, el fenómenotecnológico nos presenta nuevas aristas. Si nuestro conocimiento de lo real está condicionado por nuestra percepción y ésta, a su vez, por nuestros sentidos, podríamos afirmar que el límite de nuestro conocer está establecido por el cuerpo. Esto significa que "somos nuestro cuerpo en el sentido en que la fenomenología entiende nuestro móvil, perceptual y emotivo ser-en-el-mundo" (Ihde, 2002). En este punto es donde cobra importancia la idea de la tecnología como extensión del ser humano (del cuerpo), que McLuhan recupera de E.T. Hall: "el hombre ha desarrollado extensiones prácticamente de todo lo que solía hacer con su cuerpo, (...) todas las cosas materiales hechas por el hombre pueden considerarse como extensiones de lo que el hombre hizo un tiempo con su cuerpo o con alguna parte especializada de su cuerpo. (...) formas mecánicas extienden los miembros y los órganos, mientras que las tecnologías eléctricas extienden el sistema nervioso y el consciente y el inconsciente de una u otra manera y grado."

Si percibimos a través de la tecnología y ésta extiende nuestras capacidades perceptuales, la conclusión lógica es que la tecnología expande los límites de nuestro conocer, por tanto, de nuestro conocimiento de lo real. El peligro que esta argumentación conlleva, está directamente relacionado con una idea, un poco ingenua, de lo que significan estas "extensiones" tecnológicas. En efecto, menos cándidamente (y menos políticamente), son al mismo tiempo limitadoras y transformadoras de las capacidades perceptuales y sensoriales originarias del propio cuerpo humano. Dice Ihde: "la vista de las montañas de la luna a través del poder transformador del telescopio, la remueve de su lugar en la extensión de los cielos. Pero si nuestras tecnologías fueran sólo para replicar nuestra 
experiencia corporal e inmediata, sería de muy poca utilidad, y ultimadamente, de muy poco interés." (Ihde, 2002).

Nuestras percepciones a través de la tecnología también están determinadas por ésta. Incluso las percepciones no mediadas por tecnología alguna se ven afectadas por nuestras experiencias in-mediatas, en formas complejas que pueden llegar a lo biológico, como nos sugiere De Kerckhove: "Un experimento que recomiendo para comprobar las diferencias entre la escucha oral y la alfabética (visual) es agachar discretamente la cabeza y cerrar los ojos en la próxima reunión social. Se sorprenderá del número de diferentes conversaciones que es capaz de seguir al mismo tiempo. Luego, abra los ojos e intente seguirlas. Se dará cuenta de que esto le resulta muy difícil, sino imposible. La razón de esto es doble: en primer lugar, los ojos emplean una gran cantidad de energía mental. Nuestras funciones sensoriales son selectivas. (...) Algunos sentidos requieren más energía que otros, como, por ejemplo, la visión, que requiere dieciocho veces más energía que la audición. La visión periférica es más rápida y comprensiva que el oído, especialmente bajo las condiciones de la cultura visual."

Sin embargo, la crítica de la interpretación de McLuhan no nos impide ver su utilidad operativa a la hora de entender los dispositivos mediáticos, siempre que tengamos en cuenta hasta qué punto la sociedad y la cultura no sólo condicionan nuestras respuestas, sino también las preguntas que somos capaces de hacernos, e incluso nuestra curiosidad. En este sentido, cuando hablamos de medios es interesante recordar la afirmación de Lister, "...usamos frecuentemente el término [new media] para decir diferentes cosas. Lo usamos frecuentemente para conjurar un futuro basado en la promesa económica y educacional de los nuevos medios, o la promesa de nuevas tecnologías para formas mediáticas por venir. Es también muy seductor por su simplicidad histórica: había medios 'viejos' y ahora están los 'nuevos'. Lo usamos para marcar una ruptura con la historia." (Lister, 2003).

Nuestro conocimiento del mundo es perspectivo, subjetivo, lo que existe, existe para un sujeto percipiente. Asimismo, nuestro recorte de la realidad está fuertemente influido por nuestra pertenencia a una sociedad, a una cultura. Las dimensiones simbólicas, emocionales, interpersonales, identitarias, referenciales, predisponen al individuo en la elección delmedio. Enla coyunturaactual resulta patentecómo la elección del medio se relaciona, por ejemplo, con el grado de confiabilidad que el sujeto le otorgue. Así, la construcción de la realidad aparece condicionada por prejuicios socio-culturales que nos llevan a elegir la prensa gráfica por sobre la televisión, o la opinión de nuestros vecinos, colegas o amigos, en lugar de la radio. Cuánto influye la potencia de la imagen, la fuerza de nuestros sentidos concentrados en lo visual, de nuestra visualidad educada y marcada, en la elección del medio, es una pregunta significativa para entender los fenómenos de percepción mediática y la construcción de interpretaciones del mundo. La puesta en crisis de la percepción y comprensión del mundo es anterior a la aparición del medio, incluso podríamos decir que exterior a él y al mismo tiempo intrínseca a su naturaleza de realidad interpuesta, de intersticio ontológico, que siempre aparece cargado de sentidos. Como nos recuerda Gunning: "De hecho, los aparatos ópticos fueron también utilizados por los jesuitas durante la Contrarreforma como alegorías visuales, no solo para convencer a los iletrados de los poderes de Dios y su Iglesia sino asimismo para revelar a los instruidos la naturaleza contingente de conocimiento y percepción en nuestro mundo caído (...) tanto las exhibiciones de raciocinio y desmitificación como los enigmas religiosos y místicos se nutrieron de las ilusiones ópticas no tanto para engañar al espectador como para conseguir que reflexionara sobre la limitada y frágil naturaleza de la percepción humana. La Ciencia y la Fe podían, no obstante, acabar con estas incertidumbres." (Gunning, 2003).

Un aspecto interesante de lo anterior es la reflexión que sobre ello hacen los críticos y teóricos de los estudios culturales y, en especial, las posturas apocalípticas de algunos. Entre las varias gradaciones de alarma, sobresalto y/o pavor, ante la aparición de "nuevos medios" y sus consecuencias, cabe destacar la lectura de Jacques Aumont sobre la televisión (la pantalla pequeña): “...actualmente la mirada se ha inmovilizado o desmovilizado. Por mucho que la televisión adopte los puntos de vista que quiera, no suscitará sino la ausencia de mirada. El ojo, además, ya no es un instrumento actual sino por su capacidad de leer imágenes esquematizadas, sintetizadas, hipersignificantes. Y de leerlas deprisa, bajo 'pena de muerte' -como en los juegos de video y otras simulaciones." (Aumont, 1997). Una lectura de este tipo luego se ocupa de rastrear distintas prácticas como preanunciadoras de la aparición de nuevos medios y nos lleva a preguntarnos si existen tales prácticas preanunciantes de los medios digitales. Cabe observar aquí que la pantalla digital (o electrónica) no se propone como habitable. En algunos casos puede tener carácter inmersivo, pero nunca habitable.

Hay una diferencia profunda en el sentido del medio, la "máquina simbólica de producir punto de vista" no es difícilmente extensible hacia la fotografía y la televisión. Sin embargo queda claro que la pantalla digital, incluso genealógicamente hablando, nointenta producir (o reproducir) un punto de vista. Al respecto Eduardo Russo establece que “...las formas y tecnologías ligadas a la imagen electrónica, la constelación abierta por "lo digital", el entramado de creciente complejidad de eso que a falta de mejor nombre hoy se suele llamar como "nuevos medios" parecen responder a un deseo multiforme de nuevas imágenes y nuevas fronteras para lo visible, a convocatorias en torno a modos de representación y contacto, a prácticas de la mirada con nuevos códigos y ritos, en suma, a formas de presencia y actividad cuyo perfil se encuentra muy lejos de estar claramente trazado. De todas maneras, trascendiendo el lamento por la ceguera o por la retirada de lo visible (y tras ella, acaso, el retroceso del mundo ligado a esa visibilidad, que parece acechar en las insistentes denuncias sobre la virtualización en avance, como un declive progresivo hacia el reino del simulacro total) el estallido desde 
el terreno de esas mismas prácticas impone pensar sobre qué tipo de ojo se están configurando esas experiencias." Si es posible ver que existe una potencia proyectual en la pantalla digital como interfase, que en las anteriores se reducía a lo representacional, las nuevas fronteras difícilmente se encuentren en torno a lo visible. Quizás podríamos afirmar que el nuevo tipo de ojo es un ojo fundamentalmente cansado.

Por otro lado, Vivian Sobchack nos intenta convencer de que las metáforas de navegación e inmersión presentes en los medios digitales encubren una tendencia paradójica: requieren el ingreso, pero resulta imposible una presencia consistente en ese espacio. Nuevamente, con cierta nostalgia sobre la "habitabilidad" del cine, parece olvidar los orígenes del desarrollo de las pantallas electrónicas, la influencia de su uso como instrumento de control en tiempo real, de lo esencial de su interactividad. Hablar de nociones tan culturales como "entrar en una website" o "navegar" suena al menos inocente, ingenua, respecto de la interpretación de un medio que pertenece a una red tecnoeconómica que se ocupa, entre otras cosas, de construir una lógica de sentido para sus nuevos productos en el mercado. Como si no fuese suficiente Sobchack afirma: "La presencia de la representación electrónica es a la vez separada de las conexiones representacionales previas entre significación y referencialidad. La presencia electrónica no afirma una posesión objetiva del mundo y el yo (como la fotográfica) y un compromiso centrado y espaciotemporal con el mundo y los otros acumulado y proyectado como experiencia encarnada y conciente (como la cinematográfica) (...) devaluando la condición física del cuerpo viviente y la materialidad concreta del mundo, la presencia electrónica sugiere que estamos en peligro de convertirnos en meros fantasmas en la máquina." (Sobchack, 1994).

Pareciera que estamos ante un claro caso de lo que Don Ihde llama "Tecnofantasías": "Podemos -en una cultura tecnológica- fantasear formas en las cuales podemos ir más allá de nuestras limitaciones físicas o nuestros problemas sociales por medio de tecnologías creadas en imaginaciones utópicas. En este modo de tecnofantasía, nuestras tecnologías se convierten en nuestros ídolos y superan nuestra finitud." (Ihde, 2003). Si bien este tipo de fantasías han estado presentes durante el transcurso de la historia (desde el Golem cabalístico a los Cyborgs), parecen adquirir mayor fuerza frente a la aparición de los medios digitales: "Esta forma es a menudo la de una realidad virtual (un oxímoron) proyectada, o la cual tiene lugar en el ciberespacio, términos relacionados con nuestras fantasías acerca de nuestras tecnologías postmecánicas, electrónicas y computacionales del presente." (Ihde, 2003). Una postura, en el fondo, reticente, que revela una lectura de la tecnología como algo negativo, como algo que "envenena la originalidad y el valor para reemplazarlos por la banalidad y la monotonía." (Silverstone, 2002). Esta actitud no varía demasiado de la noción de tecnofantasía, es en la connotación de las peculiaridades que el usuario confiere al medio donde se encuentra la diferencia. Aquí, la tecnología no solamente es inútil para solucionar nuestras dificultades, sino que es la culpable de éstas. Preferimos pensar, con Russo, que "tal vez este ojo no se vea empujado hacia la ausencia de mirada, sino hacia un mirar distinto." Cabe aclarar que, a nuestro entender, no hay, en definitiva, tal ojo electrónico, sino que se trata, en todo caso, de una mente corporizada que adquiere nuevos modos de operar e interpretar.

\section{Perspectiva tecnológica}

Uno de los fragmentos más esclarecedores que hemos encontrado para entender las reacciones producidas por las "nuevas tecnologías" pertenece a Roger Silverstone: "En el sentido común y los discursos cotidianos, e incluso en los escritos académicos, las tecnologías aparecen mágicamente, son magia y tienen consecuencias mágicas (...) Las operaciones de la máquina son misteriosas y, como resultado, confundimos su origen y su significado. El uso que les damos está cargado de folclore. (...) Esta sobredeterminación da a las tecnologías mediáticas un poder considerable, por no decir pavoroso, en nuestra imaginación. Nuestra participación en ellas está impregnada por lo sagrado, mediatizada por la ansiedad, abrumada, de vez en cuando, por la alegría. Dependemos de ellas de manera sustancial. Nos sentimos completamente desesperados cuando se nos priva del acceso a ellas: el teléfono como línea de vida, la televisión como esencial ventana al mundo. Y en ocasiones, cuando nos enfrentamos a lo nuevo, nuestra emoción no conoce límites: ¿Cuatro billones de megabytes? ¡No!” (Silverstone, 2002).

Creemos que al hablar de la pantalla como dispositivo técnico, una de las primeras cuestiones a tratar es la comparación habitual que se da entre pantallas y ventanas. Hay algo que es evidente y es que ninguna pantalla ha conseguido aún que su imagen cambie cuando cambia el punto de vista del espectador. El paradigma visual-óptico presente en las pantallas se remonta al Renacimiento y la generación de un orden visual a través de un observador fijo (Alberti, Dürer, Palladio, Brunelleschi), un observador estático frente a una imagen (en movimiento o no). Lo que está claro es que si en la arquitectura este paradigma es rápidamente puesto en crisis, las pantallas parece que nunca lo han podido superar (salvo algunos desarrollos recientes que apuntan a la visión estereoscópica). Esto se debe a que, operativamente, la pantalla no es una ventana, la pantalla es un cuadro. Es un error fácil de entender y no por ello menos tendencioso. Sin embargo, también es fácil de poner en evidencia. El error se remonta al Renacimiento y actualmente podemos relacionarlo con el hecho de que la cámara, el objetivo, es, en sí mismo, una pequeña ventana. Esta ventana puede, a veces, modificar la percepción óptica, como un espejo deformante (cóncavo o convexo); pero, como dispositivo, funciona exactamente igual y es fácilmente relacionable a toda la serie de dispositivos ópticos: telescopios, periscopios, prismáticos, etc. ¿Cuál es la diferencia? La diferencia se ubica en la capacidad de registro que tienen las cámaras (en este sentido un telescopio con el adecuado dispositivo de registro puede ser una cámara, 
prueba de ello son las imágenes satelitales o estelares). Incluso un radiotelescopio puede ser una cámara, salvo que no óptica.

Por lo tanto diferenciamos dos funciones: la captación y el registro. Aquí aparece evidente el error. La imagen proyectada en la pantalla es el registro de una captación (dejamos de lado por el momento el problema de la imagen de síntesis), por lo tanto, se encuentra mucho más cerca de una pintura o un cuadro que de una ventana. Conclusión a la que llegamos junto con Manovich en su arqueología de la pantalla contemporánea. Localizamos en este dilema un afán realista de representación en simultáneo a la imaginería fantasmática de lo sobrenatural (procesos paralelos con preponderancia de uno de ellos) que se dio y se da en pintura, cine, computadoras. La imagen técnica pertenece a la categoría de las representaciones técnicas. Así como el sabor artificial, aromatizantes, perfumes, música, grabaciones, etc., algo se hace presente a los sentidos por medio de la técnica. La pantalla no funciona como una ventana, quizás opera más como un portal dimensional hacia "Flatworld". La modernidad posee una cultura visual que, de la pintura al cine, se define a través de la presencia de otro "espacio", virtual, otro mundo (aparentemente tridimensional) colocado adentro de nuestro espacio no virtual. Estos espacios existen juntos, escindidos por un marco. ¿Qué caracteriza a la pantalla? Es superficial y rectangular, parte de una sucesión de formatos ortogonales, que limitan gran parte de nuestra cultura visual (de la Gioconda a Windows). Sus proporciones prácticamente no cambiaron a lo largo de cinco siglos (una pintura del siglo XV, una pantalla de cine o un monitor de computadora). Resulta evidente cuando uno pone atención en la denominación utilizada para los tipos principales de formatos de pantallas: landscape mode y portrait mode.

Fuera de cualquier metáfora o analogía sobre la pantalla, fuera de cualquier interpretación psicológica o sociológica, lo que une a las pantallas entre sí es su operatividad como dispositivo técnico. ¿Cómo podemos describir esta operatividad? Nos imaginamos tomando una hoja de papel (rectangular, digamos A2 o A1) y decimos "esto es una pantalla". Aunque suene ridículo, lo único que necesitamos para transformar esa hoja de papel en pantalla, desde el punto de vista operativo, es una fuente de luz (y un observador). Puedo utilizar una ventana en una habitación oscura o, para hacer más amena y dúctil la demostración, podríamos utilizar un proyector (cañón láser o de diapositivas). Veamos qué ocurre si colocamos la hoja entre la imagen proyectada por el proyector y los espectadores. La hoja se transforma en pantalla, la forma original y más antigua en la que una pantalla opera técnicamente, mostrando (display) para ocultar. Si a continuación coloco la hoja de papel de tal forma que los espectadores queden situados entre el artefacto proyector y la hoja misma, obtengo la segunda aplicación operativa de la pantalla, que no es solo una mutación de la primera y aún menos una evolución. Ahora opera como superficie gráfica de proyección (si miramos el haz de luz, no vemos la imagen) y haciendo la imagen visible a un grupo mayor de personas al mismo tiempo, resolviendo dos cuestiones clave, necesitamos agrandar el tamaño de la superficie gráfica para que la vea más gente al mismo tiempo y necesitamos que sea económico y rápido poder ver varias imágenes (pensemos lo distinto que sería compartir entre todos una reproducción gráfica de la imagen en una pantalla de celular o imprimir cada imagen en una tamaño enorme).

A través de este razonamiento verificamos que el primer gran salto tecnológico que realiza la pantalla, lo realiza con el radar y la subsiguiente aparición de las pantallas electrónicas. La pantalla electrónica rompe con la larga historia de las proyecciones, para comenzar el movimiento de las pantallas de "emisión". A través de estas tres categorías operativas podemos clasificar todo el universo de las pantallas a lo largo de la historia: Retroproyección, Proyección y Emisión. Quizás más que desde el punto de vista de la teoría de los medios o dispositivos técnicos, esta última interpretación obedece a un enfoque desde el diseño, un enfoque deconstructivo del diseño, del objeto al programa; deconstrucción proyectual del dispositivo técnico, introyección, retroyección. La tecnología se define por su uso y su operatividad. Para identificar los usos que el ser humano les da a los medios, es posible apoyarse en la tipología clásica de Denis McQuail, quien identificó cuatro ramas principales: diversión, que incluye el escape de la realidad, la evasión de los problemas y el desahogo emocional; relaciones personales, como la compañía y la utilidad social; identidad social, que abarca la referencia personal, la exploración de la realidad y el refuerzo de valores; y supervisión, cuya función es la obtención de información. La operatividad es definida por el diseñador (en un sentido amplio que incluye al inventor). Un ejercicio interesante que nos queda pendiente: la retroyección a las condiciones programáticas iniciales, relaciones entre: escala, tamaño, cantidad de espectadores, calidad de la imagen, costo, prácticas culturales (screen practices), portabilidad, etc. La generación casi surrealista de objetos híbridos que, hasta que no se materializan y simbolizan, recuerdan a seres mitológicos, quimeras absurdas.

\section{Conclusiones}

Las pantallas son dispositivos casi omnipresentes en nuestro hábitat. Las metrópolis en las que vivimos se encuentran cada vez más tapizadas de estos extraños portales dimensionales. Nuestras imágenes y textos nos son mostrados por pantallas, el trabajo, el placer, la comunicación, la diversión, mediados por pantallas. El cine, las computadoras, los teléfonos celulares, la televisión y toda una serie de dispositivos que incluyen agendas electrónicas, pantallas gigantes en recitales y eventos deportivos, cámaras fotográficas digitales, reproductores de música, relojes, sistemas de diagnóstico por imágenes, publicidad en la vía pública, cajeros automáticos, sistemas de navegación satelital, videojuegos, fachadas inteligentes, puntos de información turística, publimática en medios de transporte, reproductores de video, radares, stands 
y espacios de promoción, sistemas de control y vigilancia, salas de videoconferencia, escenografías televisivas, y todo tipo de displays... pantallas ubicuas, pantallas dentro de pantallas...

¿Es la pantalla la única verdadera revolución técnica en los soportes expresivos-comunicacionales después de la imprenta? Podemos afirmar que a la era previa a las pantallas podría ser definida como aquella perteneciente a los soportes técnico-expresivo-comunicacionales no-lumínicos, soportes que se visualizan como el general de los objetos, a través de la luz reflejada por ellos (libros, revistas, cuadros, láminas, afiches, etc.).

Hemos explorado una serie de intuiciones. Hemos revisado el pensamiento de algunos autores. Hemos recorrido un camino pavimentado de palabras esdrújulas: genealógica, tecnológica, analógica, fenomenológica, ontológica, ecléctica, técnica, electrónica. Y al final pareciera que las lastimeras protestas de los pastores de la era Gutemberg y todas sus predicciones apocalípticas sobre la "cultura de la imagen", parecen ignorar la enorme cantidad de cultura oral, ritual, metafísica, gestual, etc., que se ha visto obligada a desaparecer lentamente al no pasar por el filtro expresivo-comunicacional que impone el texto impreso, o aquella otra que ha sido transformada por el soporte a tal punto de dejar de ser lo que era. El terreno de los "ambientes cognitivos" (libros, pantallas, etc.) evidencia el aserto de de Kerckhove cuando propone una coevolución de hombres y máquinas.

Concluimos con una afirmación que ya hemos señalados y sobre la que corresponde insistir: ningún dispositivo técnico o soporte es un simple, inocente y transparente, recipiente para un contenido. Una noción que hoy en día parece obvia, pero que no podemos dejar de hacer evidente cada vez que hablamos de tecnologías. "Los medios que pretenden mostrar al mundo como es tienen esta intención de volverse trasparentes, impulsados por un doble deseo contradictorio: quiero la transformación que la tecnología me permite, pero la quiero de tal manera que esté básicamente inadvertido de su presencia. La quiero de tal forma en que se convierta en mí." (Ihde, 2002). Hay que mantener una mirada crítica que nos evite caer en la trampa de la naturalización.

\section{Agradecimientos}

Agradecemos a la Universidad de Buenos Aires en la cual desarrollamos nuestras investigaciones gracias a la beca doctoral otorgada y en particular a la Dra. Beatriz Galán y el Dr. Wolfgang Schäffner.

\section{Referencias}

Aumont, Jacques, El ojo interminable, Barcelona, Paidós, 1997. Bellour, Raymond, "La doble hélice", 1999. Traducción de Eduardo Russo.

Comolli, Jean-Louis, "El lado de la sombra", en Diccionaire des Utopies bajo la dirección de Michèle Riot-Sarcey, Larousse, 2002. Dartigues, A., Mente, mundo y acción, Barcelona, Paidós, 1981. Dubois, Phillipe, "Máquinas de imágenes: una cuestión de línea general", Del libro: Video, Cine, Godard, Philippe Dubois, Libros del Rojas, Universidad de Buenos Aires, 2000.

Gunning, Tom. "La fantasmagoría y la fábrica de ilusiones mágicas: hacia una óptica cultural del aparato cinematográfico". Traducción: María Calzada. "Dispositif(s) du cinéma (des premiers temps)", en Cinémas, volumen 14, n¹, otoño (2003).

Huhtamo, Erkki, Elements of screenology, 2001.

Ihde, Don, Bodies in Technology, 2002.

Lister, M. et al., New Media: A Critical Introduction. London: Routledge. 2003.

Manovich, Lev, "Una arqueología de la pantalla de computadora" en AA.VV. La revolución hipermedia, Bs. As., Expediciones2, 2000.

Silverstone, Roger, "From audiences to consumers: the household and the consumption of communication and information technologies", en European Journal of Communication, vol. 6, núm. 2, junio 1991, Sage Publications. Silverstone, Roger, "De la sociología de la televisión a la sociología de la pantalla. Bases para una reflexión global", en Diálogos de la Comunicación, núm. 33, 2004.

Sobchack, Vivian, "The Scene of the Screen: Envisioning Cinematic and Electronic Presence" en Gumbrecht Hans Ulrich, and Pfeiffer, K. Ludwig (eds.), Materialities of Communication., (Stanford: Stanford University Press, 1994). 